\title{
Commentary
}

\section{Risk Factors and Mechanisms of Alzheimer's Dis- ease Pathogenesis: Obviously and Obviously Not}

\author{
Mark P. Mattson ${ }^{*}$

\section{Laboratory of Neurosciences, National In- stitute on Aging, Baltimore, USA}

In their article, Chen and Fernandez (3) present a viewpoint in which they briefly consider the roles of the aging process, and risk factors associated with age-related degenerative diseases, in the pathogenesis of Alzheimer's disease (AD). The authors forward both the general perspective, and a specific mechanism which they suggest underlies most cases of AD. They propose that 1) "several known risk factors most likely play a critical role in the late-onset sporadic $\mathrm{AD}$ ", and 2) "plaques and tangles occur spontaneously during aging as a result of a natural decline of energy metabolism and $\mathrm{Ca}^{2+}$ signaling." $\mathrm{My}$ responses to these two major conclusions are that 1) obviously, genetic and environmental risk factors play important roles in the pathogenesis of $\mathrm{AD}$, and this is certainly not a new perspective; and 2) the proposal that a decline in energy metabolism and $\mathrm{Ca}^{2+}$ signaling is central to the pathogenesis of $\mathrm{AD}$ is obviously not correct. In the following paragraphs I will elaborate on these two points.

It is obviously the case that there are several important risk factors that increase the probability of developing $\mathrm{AD}$. The aging process is the strongest risk factor for $\mathrm{AD}$, and the molecular and cellular changes that occur in the brain dur-

\footnotetext{
* Corresponding author: Mark P. Mattson, Laboratory of Neurosciences, National Institute on Aging - GRC 4F01, 5600 Nathan Shock Drive, Baltimore, MD 21224, USA, Tel.: +1 410558 8462, Fax: +1 410558 8465, E-mail: mattsonm@grc.nia.nih.gov
}

ing aging are therefore germane to the pathogenesis of $\mathrm{AD}$. However, there are clearly additional genetic and environmental risk factors that impact on events occurring at the molecular, biochemical and cellular levels in AD. Several excellent examples of risk factors were presented nicely by Chen and Fernandez. Genetic risk factors include apolipoprotein $\mathrm{E}$ allele variations with the E4 allele increasing risks for $\mathrm{AD}$ (25). The mechanism whereby apolipoprotein $\mathrm{E}$ isoforms modify vulnerability of neurons during aging and in $\mathrm{AD}$ appears to involve an antioxidant-like property of apolipoprotein E (20) with apolipoprotein E2 being very effective in binding to and detoxifying the neurotoxic product of membrane lipid peroxidation, 4-hydroxy-nonenal (22). A deletion at the 5' splice site of exon II of $\alpha 2$ macroglobulin also increases risk for AD (1), although the precise mechanism remains to be determined. Environmental risk factors having to do with diet and behavior are becoming clearer. One of the major risk factors for $\mathrm{AD}$ that is emerging from recent work is high calorie intake or overeating, a known risk factor for other agerelated diseases including cardiovascular disease, diabetes and cancer. Recent epidemiological data suggest that individuals with a low calorie intake are at reduced risk for AD and Parkinson's disease $(8,15,19)$. Experimental data also support the possibility that reducing calorie intake will reduce risks for, and severity of, several agerelated neurodegenerative disorders including AD. Administration of the excitotoxin kainate to adult rats results in selective damage to hippocampal neurons and impaired learning and memory. Maintenance of rats on a dietary restriction regiment results in increased resistance of hippo- 
campal neurons to kainate-induced damage and amelioration of deficits in learning and memory (2). In addition, maintenance of presenilin $1 \mathrm{mu}-$ tant knockin mice on a dietary restriction regimen results in reduced levels of oxidative stress and reduced neuronal damage following kainate administration (27). Similar beneficial effects of dietary restriction have been reported in experimental animal models of Parkinson's disease, Huntington's disease and stroke $(2,5,26)$. Data in the latter studies suggest that the beneficial effect of dietary restriction involves a "pre-conditioning response" in which levels of stress proteins and neurotrophic factors are increased. The latter mechanism is of considerable interest when considering the mechanism whereby increased education reduces risk for AD (13). When taken together with animal studies in which rodents are raised in an "intellectually enriched environment (6), the available data suggest that using your brain increases its resistance to age-related neurodegenerative disorders such as $\mathrm{AD}$.

It is now very clear, based on considerable data from analyses of $\mathrm{AD}$ patients and experimental models of $\mathrm{AD}$, that many of the fundamental cellular and molecular events that occur in the brain in this disorder are also manifest in organ systems other than the brain. For example, it is very clear that alterations in energy metabolism occur in AD patients and apparently precede the neurodegenerative process. Brain imaging studies clearly reveal decreased glucose uptake into neurons in the brains of AD patients (12), and APP mutant transgenic mice exhibit reduced glucose uptake that becomes evident in the early stages of amyloid deposition (4). This alteration may result from oxidative impairment of glucose transporters caused by amyloid $\beta$-peptide deposition in conjunction with age-related increases in oxidative stress (16). In addition, studies of peripheral cells, such as fibroblasts, from AD patients suggest that deficits in energy metabolism are not limited to the brain (7). Moreover, recent studies of APP mutant transgenic mice demonstrate profound alterations in stress responses and energy metabolism (23). The latter study showed that APP mutant transgenic mice exhibit altered regulation in blood glucose levels following sev- eral different stresses, including restraint stress and food deprivation, such that the animals become severely hypoglycemic. A second example of widespread alterations in $\mathrm{AD}$ concerns functions of the immune system. Many studies have documented alterations in lymphocyte signaling and function in $\mathrm{AD}$ patients (11). Our recent studies of presenilin 1 mutant mice and APP mutant mice suggest related alterations occur in the immune system of these mouse models of AD (manuscript in preparation).

The author's contention (3) that plaques and tangles arise from a deficit in $\mathrm{Ca}^{2+}$ signaling is, in my view, not only unfounded, but exactly opposite of what available data suggest. Many different laboratories have provided evidence obtained from analyses of $\mathrm{AD}$ patients and experimental animal and cell culture models, that there is an increase in intracellular $\mathrm{Ca}^{2+}$ levels in neurons that occurs during aging and in $\mathrm{AD}$, and that the increase in intracellular $\mathrm{Ca}^{2+}$ levels contributes to the demise of the neurons. For example, Landfield and colleagues (1) have shown that calcium influx increases in hippocampal neurons during aging in rodent, and Nixon and coworkers (21) have clearly shown that activation of $\mathrm{Ca}^{2+}$ dependent proteases increases in degenerating neurons in $\mathrm{AD}$. We have shown that increases in intracellular $\mathrm{Ca}^{2+}$ levels can elicit changes in the cytoskeleton of neurons similar to those seen in neurofibrillary tangles $(17,24)$, and that amyloid $\beta$-peptide disrupts $\mathrm{Ca}^{2+}$ regulation in a manner that increases $\mathrm{Ca}^{2+}$ influx and increases vulnerability of neurons to various insults relevant to AD including excitotoxicity and apoptosis (18). Moreover, a primary effect of presenilin-1 mutations is to disturb $\mathrm{Ca}^{2+}$ regulation in the endoplasmic reticulum which results in enhanced levels of intracellular $\mathrm{Ca}^{2+}$ following exposure of neurons to oxidative, metabolic and excitotoxic insults $(9,10)$. The author's (3) contention that $\mathrm{Ca}^{2+}$ signaling potency is reduced during aging is directly against an overwhelming body of evidence showing that age-related changes known to occur in the brain, including increased oxidative stress and decreased energy availability, promote increases in intracellular $\mathrm{Ca}^{2+}$ levels rather than decreases. Thus, oxidative stress impairs the 
function of ion-motive ATPases and other $\mathrm{Ca}^{2+}$ regulating proteins which promote membrane depolarization and $\mathrm{Ca}^{2+}$ influx. Similarly, reduced glucose availability to neurons results in reduced ATP levels and reduced ability of neurons to remove $\mathrm{Ca}^{2+}$ via energy dependent pumps. Finally, the known risk factors for $\mathrm{AD}$ would also tend to promote elevations in intracellular $\mathrm{Ca}^{2+}$ levels. For example, head trauma and cerebral ischemia both increase intracellular $\mathrm{Ca}^{2+}$ levels in neurons which contributes to their degeneration under these adverse conditions. Moreover, the emerging mechanism for the beneficial effects of dietary restriction, and activity in neuronal circuits, involves stabilization of intracellular calcium levels as the result of enhanced neurotrophic factor signaling and stress protein production $(5,26)$.

In conclusion, the article by Chen and Fernandez (3) provides a useful, albeit obvious, view of the importance risk factors for AD pathogenesis. On the other hand, the authors appear to be quite off the mark concerning the roles of dysregulation of $\mathrm{Ca}^{2+}$ homeostasis and energy metabolism in the pathogenesis of $\mathrm{AD}$.

\section{REFERENCES}

1. Blacker D, Wilcox MA, Laird NM, Rodes L, Horvath SM, Go RC, Perry R, Watson Jr B, Bassett SS, McInnis MG, Albert MS, Hyman BT, Tanzi RE, Alpha-2 macroglobulin is genetically associated with Alzheimer disease, Nat Genet 19 (1998) 357-360.

2. Bruce-Keller J, Umberger G, McFall R, Mattson $\mathrm{MP}$, Food restriction reduces brain damage and improves behavioral outcome following excitotoxic and metabolic insults, Ann Neurol 45 (1999) $8-15$.

3. Chen M, Fernandez HL, Revisiting Alzheimer's disease from a new perspective: can "risk factors" play a key role?, J Alz Dis (2000) 97-108.

4. Dodart JC, Mathis C, Bales KR, Paul SM, Ungerer A, Early regional cerebral glucose hypometabolism in transgenic mice overexpressing the V717F $\beta$-amyloid precursor protein, Neurosci Lett 277 (1999) 49-52.

5. Duan W, Mattson MP, Dietary restriction and 2deoxyglucose administration improve behavioral outcome and reduce degeneration of dopaminergic neurons in models of Parkinson's disease, J Neurosci Res 57 (1999) 195-206.

6. Falkenberg T, Mohammed AK, Henriksson B, Persson H, Winblad B, Lindefors N, Increased expression of brain-derived neurotrophic factor mRNA in rat hippocampus is associated with improved spatial memory and enriched environment, Neurosci Lett 138 (1992) 153-156.

7. Gibson G, Martins R, Blass J, Gandy S, Altered oxidation and signal transduction systems in fibroblasts from Alzheimer's patients, Life Sci 59 (1996) 477-489.

8. Grant W, Dietary links to Alzheimer's disease, Alz Dis Rev 2 (1997) 42-55.

9. Guo Q, Sopher BL, Pham DG, Furukawa K, Robinson N., Martin GM, Mattson MP, Alzheimer's presenilin mutation sensitizes neural cells to apoptosis induced by trophic factor withdrawal and amyloid $\beta$-peptide: involvement of calcium and oxyradicals, J Neurosci 17 (1997) 4212-4222.

10. Guo Q, Fu W, Sopher BL, Miller MW, Ware CB, Martin GM, Mattson MP, Increased vulnerability of hippocampal neurons to excitotoxic necrosis in presenilin-1 mutant knockin mice, Nature Med 5 (1999) 101-107.

11. Ibarreta D, Parrilla $\mathrm{R}$, Ayuso MS, Altered $\mathrm{Ca}^{2+}$ homeostasis in lymphoblasts from patients with late-onset Alzheimer disease, Alzheimer Dis Assoc Disord 11 (1997) 220-227.

12. Jagust WJ, Seab JP, Huesman RH, Valk PE, Mathis CA, Reed BR, Coxson PG, Budinger TF, Diminished glucose transport in Alzheimer's disease: Dynamic PET studies, J Cereb Blood Flow Metab 11 (1991) 323-330.

13. Katzman R, Education and the prevalence of dementia and Alzheimer's disease, Neurology 43 (1993) 13-20.

14. Landfield PW, Aging-related increase in hippocampal calcium channels, Life Sci 59 (1996) 399404.

15. Logroscino G, Marder K, Cote L, Tang MX, Shea $\mathrm{S}$, Mayeux R, Dietary lipids and antioxidants in Parkinson's disease: a population-based, casecontrol study, Ann Neurol 39 (1996) 89-94.

16. Mark RJ, Pang Z, Geddes JW, Mattson MP, Amyloid $\beta$-peptide impairs glucose uptake in hippocampal and cortical neurons: involvement of membrane lipid peroxidation, J Neurosci 17 (1997) 1046-1054.

17. Mattson MP, Antigenic changes similar to those seen in neurofibrillary tangles are elicited by glu- 
tamate and calcium influx in cultured hippocampal neurons, Neuron 4 (1990) 105-117.

18. Mattson MP, Cheng B, Davis D, Bryant K, Lieberburg I, Rydel RE, $\beta$-amyloid peptides destabilize calcium homeostasis and render human cortical neurons vulnerable to excitotoxicity. J Neurosci 12 (1992) 376-389.

19. Mayeux R, Costa R, Bell K, Merchant C, Tung MX, Jacobs D, Reduced risk of Alzheimer's disease among individuals with low calorie intake, Neurology 59 (1999) S296-297.

20. Miyata M, Smith JD, Apolipoprotein E allelespecific antioxidant activity and effects on cytotoxicity by oxidative insults and beta-amyloid peptides, Nature Gen 14 (1996) 55-61.

21. Nixon RA, Saito KI, Grynspan F, Griffin WR, Katayama S, Honda T, Mohan PS, Shea TB, Beerman M, Calcium-activated neutral proteinase (calpain) system in aging and Alzheimer's disease, Ann NY Acad Sci 747 (1994) 77-91.

22. Pedersen WA, Chan SL, Mattson MP, A mechanism for the neuroprotective effect of apolipoprotein E: isoform-specific modification by the lipid peroxidation product 4-hydroxynonenal, J Neurochem 74 (2000) 1426-1433.

23. Pedersen WA, Culmsee C, Ziegler D, Herman JP, Mattson MP, Aberrant stress response associated with severe hypoglycemia in a transgenic mouse model of Alzheimer's disease, J Mol Neurosci 13 (1999) 159-165.

24. Stein-Behrens B, Mattson MP, Chang I, Yeh M, Sapolsky RM, Stress excacerbates neuron loss and cytoskeletal pathology in the hippocampus, J Neurosci 14 (1994) 5373-5380.

25. Strittmatter WJ, Roses AD, Apolipoprotein E and Alzheimer's disease, Annu Rev Neurosci 19 (1996) 53-77.

26. Yu ZF, Mattson MP, Dietary restriction and 2deoxyglucose administration reduce focal ischemic brain damage and improve behavioral outcome: evidence for a preconditioning mechanism, J Neurosci Res 57 (1999) 830-839.

27. Zhu H, Guo Q, Mattson MP, Dietary restriction protects hippocampal neurons against the deathpromoting action of a presenilin-1 mutation, Brain Res 842 (1999) 224-229. 